\title{
EDUCAÇÃO DO CAMPO E AGROECOLOGIA: ARTICULANDO PRÁTICA, MOVIMENTO SOCIAL E CIÊNCIA
}

\section{Rural Education and Agroecology: articulating practice, social movement and science}

\author{
Caroline Lins Ribeiro Ferreira ${ }^{1}$ \\ Kelci Anne Pereira ${ }^{2}$
}

RESUMO: Este artigo objetiva compreender e relacionar as categorias Educação do Campo e Agroecologia, contextualizadas na referência epistemológica e filosófica do materialismo histórico, identificando algumas de suas aproximações. Partimos da seleção, revisão bibliográfica e síntese de obras que sistematizam matrizes formativas destas duas categorias, utilizando a leitura crítica como principal procedimento. Como resultado, verificamos que ambas se articulam a partir de três eixos principais, que as originam e sustentam, a saber: prática, movimento social e ciência. De um lado, tais categorias compartilham dilemas frente ao desafio de construção de sociedades justas e sustentáveis; de outro, anunciam e sistematizam projetos contra-hegemônicos de educação e produção agrícola em bases recíprocas do binômio sociedade-natureza, no sentido de contribuir para um modelo popular de reforma agrária, de territorialização do campesinato e de organização da sociedade.

Palavras-chaves: Educação do Campo. Agroecologia. Transformação.

ABSTRACT: This article aims to understand and relate the categories Rural Education and Agroecology, contextualized in the epistemological and philosophical reference of historical materialism, identifying some of their approaches. We start from the selection, bibliographic review and synthesis of works that systematize formative matrices of these two categories, using critical reading as the main procedure. As a result, we found that both are articulated from three main axes, which originate and sustain them, namely: practice, social movement and science. On the one hand, these categories share dilemmas in the face of the challenge of building just and sustainable societies; on the other hand, they announce and systematize counter-hegemonic projects of education and agricultural production based on reciprocal bases of the society-nature binomial, in the sense of contributing to a popular model of agrarian reform, the territorialization of the peasantry and the organization of society.

Key-words: Rural education. Agroecology. Transformation.

\footnotetext{
${ }^{1}$ Doutora em Ciências Ambientais pela Universidade Federal de São Carlos (UFSCar). Educadora e sócia fundadora da Associação Cultural Quintal Aroeira - Bertioga (SP). E-mail: clinstibeiro@gmail.com

${ }^{2}$ Doutora em Educação pela Universidade de São Paulo (USP). Professora do curso de Licenciatura em Educação do Campo (LEdoC), da Universidade Federal do Piauí (UFPI), Campus Professora Cinobelina Elvas (CPCE), em Bom Jesus (PI). E-mail: kelcipereira@gmail.com
} 


\section{CONSIDERAÇÕES INICIAIS}

Como parte de uma pesquisa de doutorado ${ }^{3}$, fizemos uma breve sistematização das categorias "Educação do Campo" e "Agroecologia", sem o intento de apresentar um único ponto de vista sobre elas, mas de apresentar o nosso posicionamento frente a disputa existente em suas materialidades de origem.

Ancoradas nas orientações descritas por Lima; Mioto (2007, p. 39) no método dialético, consideramos a "contradição e o conflito; o 'devir'; o movimento histórico; a totalidade e a unidade dos contrários" na construção do estudo. Iniciamos com a seleção de algumas das principais obras que discutem sistematicamente as matrizes da agroecologia e da Educação do Campo, selecionando verbetes do Dicionário da Educação do Campo (CALDART et al., 2012), além de artigos e teses disponíveis na base Scielo e no Banco de Teses e Dissertações da Capes. Utilizamos o procedimento de leitura investigativa (além de anotações), para o levantamento e a seleção da fundamentação teórico-bibliográfica utilizada e, por fim, elaboramos uma síntese integradora das categorias estudadas.

A seguir, apresentamos o dados e análises da pesquisa.

\section{EDUCAÇÃO DO CAMPO}

A Educação do Campo (EdoC), integrante da história da educação popular brasileira, se configura originalmente como prática social ligada a projeto coletivo de emancipação camponesa. Nesse sentido, tendo dos movimentos sociais do campo como seu principal sujeito, ela emerge das necessidades formativas identificadas no processo de luta por reforma agrária e de disputa pela terra e território. Emerge também, da busca sistemática dos educadores-militantes por consolidar estratégias político pedagógicas de educação para além do capital, como defendeu Mészarós (2006), ou de educação emancipatória, como argumentou Ribeiro (2013), se configurando como um conjunto plural de práticas educativas formais e não formais.

\footnotetext{
${ }^{3}$ A pesquisa "Educação ambiental dialógico-crítica e sua relação com a prática da Agroecologia e da Educação do Campo no território do extremo sul da Bahia: entre o descompasso e o desafio de transformação" foi desenvolvida no Programa de Pós-Graduação em Ciências Ambientais da Universidade Federal de São Carlos (UFSCar), com defesa em 2019.
} 
O pano de fundo dessas práticas é a indissociabilidade entre a conquista dos meios materiais e dos meios culturais e educativos de reprodução (ampliada) da vida pelos trabalhadores do campo, pressuposta na construção da contra-hegemonia ${ }^{4}$ (WILLIAMS, 1979).

A materialidade de origem da Educação do Campo demarca, portanto, a opressão a que historicamente os camponeses foram submetidos no Brasil, pelo prisma da violência, da violação (STEDILE, 2012) e da falta - falta do direito à terra, à educação, à comunicação, à moradia. Mas indica também, o potencial de organização dos sujeitos coletivos do campo para definirem para si um outro lugar na História e para reivindicar do Estado, sem transferir-lhe o protagonismo, a responsabilidade pública por reconhecê-los como sujeitos de direitos e portadores de conhecimentos. Conhecimentos estes, que estão fortemente ligados ao patrimônio genético alimentar brasileiro e à socioagrobiodiversidade (CARVALHO, 2013).

Em síntese, podemos dizer que a Licenciatura em Educação do Campo (LEdoC), como prática, nasce de uma exigência dos movimentos sociais camponeses em definir os rumos de seu próprio processo educativo, sem abrir mão do patrimônio cultural da humanidade - legado pela ciência, pela Filosofia e pela arte - que a escola tem por função socializar. Mas, não se trata, neste caso, de achar frestas para uma inserção subordinada no modelo burguês de escola que o capitalismo difundiu como uma exigência de sua própria manutenção. Os lutadores da Educação do Campo exigiram desde suas primeiras reivindicações, uma escola ligada à vida, aos seus problemas e necessidades de seus sujeitos - necessidades cognitivas, políticas, sociais - uma escola que organize a experiência em relação ao conhecimento para que este se torne instrumento de intervenção e transformação da realidade e de metaforização de si. Trata-se, portanto, de uma escola ligada aos saberes do trabalho (em sentido ontológico, além de produtivo), incluindo prioritariamente, o trabalho de co-evolução dos seres humanos e da natureza na produção dos meios de vida, de representação desse processo e luta por garanti-lo, por meio das linguagens e da auto-organização.

Camini (2009) evidencia que são nos assentamentos, sob a lona preta e com esforços de educadores militantes voluntários, intelectuais orgânicos, que esta escola de educação popular se inicia, mas também, realça que para os movimentos camponeses, a noção de escola é alargada e inclui as marchas de luta por reforma agrária, os congressos do povo, a labuta cotidiana de organização de base, as místicas dos movimentos etc. A experiência de atuação nesses processos

\footnotetext{
${ }^{4}$ Recuperando Gramsci, Williams (1979, p. 114) aborda a construção de uma hegemonia alternativa "pela conexão prática de muitas formas diferentes de luta, inclusive as que não são facilmente identificáveis como 'políticas' e 'econômicas' [...]. As fontes de qualquer hegemonia alternativa são, na verdade, difíceis de definir. Para Gramsci, elas nascem da classe trabalhadora, mas não essa classe como uma construção ideal ou abstrata. O que ele vê é antes uma classe trabalhadora que tem, precisamente, de se tornar uma classe, e uma classe potencialmente hegemônica, contra as pressões e limites de uma hegemonia existente e poderosa."
} 
organizados intencionalmente para produzirem processos de conhecimento da realidade faz parte do que podemos chamar de Educação do Campo, muito embora, a educação, como prática social, seja hoje muito mais ampla do que as experiências conduzidas pelos movimentos camponeses.

Nesse sentido é que realçamos o papel do movimento social por uma Educação do Campo na ampliação da própria prática social da Educação do Campo. E, para evidenciar esse alargamento, convém recuperar o histórico de mais de 20 anos da Educação do Campo no Brasil.

Segundo Caldart (2012, p. 257), a expressão Educação do Campo tem seu nascedouro na I Conferência Nacional de Educação Básica do Campo, em Goiás, no ano de 1998, com as discussões sobre a Educação Básica do Campo. O contexto social mostrava-se favorável para o avanço das lutas por reforma agrária e para a atuação do Movimento dos Trabalhadores Sem Terra (MST), dada a sensibilização da sociedade após os massacres camponeses de Corumbiara (Rondônia - 1995) e de Eldorado dos Carajás (Pará - 1996).

Nesse contexto, os movimentos sociais se organizavam para lograr do Estado uma política pública participativa que, ao mesmo tempo, legitimasse o movimento social como agente educador e incentivasse as instituições de Ensino Superior do Brasil a participarem, com o Instituto Nacional de Colonização e Reforma Agrária (INCRA), em regime tripartite, da gestão de projetos educacionais para as áreas de assentamento, com iniciativas inicialmente ligadas à alfabetização de pessoas adultas. Nasceu assim, em 1998, o Programa Nacional de Educação na Reforma Agrária (PRONERA), tendo seu conceito e propósitos reafirmados, aprimorados e fortalecidos nos anos de 2002 e 2004, tanto no Seminário Nacional em Brasília, como na II Conferência Nacional de Educação Básica do Campo (SANTOS, 2012).

Sob impulso do PRONERA, ao longo dos anos, deu-se a aproximação dos movimentos sociais camponeses, com os movimentos sindicais do campo, pastorais, ligas e outras entidades, junto a universidades e agentes públicos educativos de estados e municípios em torno da defesa da Educação do Campo. Não sem contradições e tensões, tais sujeitos foram conformando uma pauta e uma maneira comum pela qual lutar, formando um sentimento de pertencimento e um repertório de ação compartilhada denominado Movimento Nacional por uma Educação do Campo, que se agrega no Fórum Nacional de Educação do Campo (FONEC).

Nesse processo, conquistas legais foram logradas, inserindo o conjunto dos povos do campo, para além dos assentados da reforma agrária, como sujeitos de direito à educação e reconhecendo-se a educação como uma modalidade de educação (que dialoga com os métodos da pedagogia da alternância) Básica e Superior. Entre tais conquistas, destacamos: as resoluções CNE/CEB 4/2000, CNE/CEB 1/2002 e 2/2008; o Decreto 7352/2010; o Programa de Apoio à 
Formação Superior em Licenciatura em Educação do Campo (Procampo) e o Programa Nacional de Educação do Campo (Pronacampo).

Ao tornar-se um direito legalmente reconhecido e amparado por políticas específicas, a prática social da Educação do Campo se amplia, conformando-se como indicador positivo entre luta social e democracia. No entanto, ampliam-se também, as contradições quanto às concepções e métodos educativos enfeixados sob o termo Educação do Campo e aumenta a desagregação política das iniciativas; muitas surgem isoladas do movimento, induzidas por chamadas públicas com financiamento, como é o caso de algumas LEdoCs, por exemplo. A tensão interna sobre o que e como se caracteriza a Educação do Campo, evidenciando variadas posições entre movimentos, grupos acadêmicos, gestores públicos, por exemplo, são ampliadas com tensionamentos vindos do lado de fora.

As organizações do setor patronal, interessadas em manter a subordinação do trabalho e da natureza pelo capital no campo, por meio do aparato educativo, atua diuturnamente para desmontar os processos de acumulação de forças em defesa da reforma agrária popular e para sobrepor à concepção de Educação do Campo ao paradigma da Educação Rural, que equivale à educação bancária ${ }^{5}$ caracterizada por Freire (2001). Não raramente, o setor patronato rural, com suas entidades sindicais e bancada no congresso, interfere para o esvaziamento de algumas políticas de educação tecnológica, captando a renda da terra ao receber financiamento do estado para a execução de programas de profissionalização rural ligados ao paradigma do capitalismo agrário (FERNANDES, 2009).

Orientada para explicar os fenômenos anteriormente descritos, a Educação do Campo se forma como ciência que também está em disputa. De um lado, temos o paradigma do capitalismo agrário, ligado à redução da Educação do Campo à educação bancária/rural pensada pela burguesia e direcionada de forma depositária aos camponeses, para incorporá-los de modo subordinado e a suas terras na reprodução do capital (OLIVEIRA; CAMPOS, 2012, p. 240). De outro, o paradigma da questão agrária (FERNANDES, 2009), que considera indissociável a garantia dos direitos à terra, ao território e à educação. Na perspectiva do paradigma da questão agrária, encontramos a valorização do conceito de camponês ou de campesinato, como classe social formada por sujeitos plurais e a defesa dos movimentos camponeses e sindicais, preocupados com a escolarização dos sujeitos do campo como agentes educadores.

\footnotetext{
${ }^{5}$ O conceito de educação bancária, formulado por Freire (2001), diz respeito a um tipo de educação baseada na transferência (ou depósito) de conhecimentos para adaptação dos educandos ao mundo desigual, distanciando-os do cultivo do espírito crítico e da vontade de transformação. A educação bancária envolve práticas pedagógicas que incentivam a alienação e a submissão, ancoradas em uma compreensão da realidade como algo imutável.
} 
Diante desses antagônicos paradigmas, nos orientamos pela base teórico-metodológica da Educação do Campo com enfoque na questão agrária, compreendo-a como uma categoria fundada no tripé campo-política pública-educação (CALDART, 2012). O pilar do campo realça a permanência histórica do latifúndio (ora agroexportador ora improdutivo) e de suas consequências de violação dos direitos humanos e da natureza no Brasil, escamoteado no conceito de agronegócio; ao mesmo tempo em que reconhece e valoriza as lutas camponesas pelo acesso à terra e ao território (FERNANDES; MOLINA, 2004).

O pilar das políticas públicas reconhece o aparato estatal como espaço de disputa das classes e o governo como resultado dessas disputas, entendendo que as políticas públicas só podem ser corretivas de dívidas históricas, se formuladas e controladas socialmente, agregando-se o princípio da igualdade na diversidade à equidade (dar mais a quem tem menos) (MOLINA, 2012).

O pilar da educação, por sua vez, se refere a um processo amplo de formação omnilateral ${ }^{6}$ e de desenvolvimento humano integral, que reconhece os camponeses como sujeitos capazes de projetar o seu próprio futuro, de obterem democraticamente o acesso ao conhecimento acumulado historicamente, aprimorando-os, refutando-os e/ou utilizando-os em favor de suas reivindicações (CALDART, 2012), o que Freire (2001) chamaria de Pedagogia do Oprimido.

Sobre a questão educacional, Caldart (2012, p. 263) afirma que,

como referência de futuro à educação dos trabalhadores, a Educação do Campo recoloca desde sua luta específica a questão sempre adiada na história brasileira da efetiva universalização do direito à educação, tensionando na esfera da política formas e conteúdos de ações do Estado nessa direção. E se buscar confrontar a lógica que impede os trabalhadores de ter acesso pleno à educação básica não é ainda a "revolução brasileira", na prática, a superação do capitalismo não se realizará sem passar por este confronto e sua solução.

Nesse sentido, a Educação do Campo articula experiências históricas de educação protagonizadas pelos trabalhadores do campo, para fortalecer a compreensão de que a "questão da educação não se resolve por si mesma e nem apenas no âmbito local”' (CALDART, 2012, p. 263), devendo apresentar um direcionamento político intencional. Nas palavras da autora, trata-se de um tipo de educação

protagonizado pelos trabalhadores do campo e suas organizações, que visam incidir sobre a política de educação desde os interesses sociais das comunidades

\footnotetext{
${ }^{6}$ Educação omnilateral é uma concepção de formação humana que leva em consideração todas as dimensões que constituem a especificidade do ser humano e as condições objetivas e subjetivas reais para o seu pleno desenvolvimento histórico. Envolve a vida corpórea material, o desenvolvimento intelectual, cultural, educacional, psicossocial, estético, afetivo, estético e lúdico. Essas esferas, especificamente humanas, advêm de um processo no qual o ser se constitui socialmente por meio do trabalho (FRIGOTTO, 2012).
} 
camponesas. Objetivo e sujeitos remetem às questões de trabalho, da cultura, do conhecimento e das lutas sociais dos camponeses e ao embate (de classe) entre projetos de campo e entre lógicas de agricultura que têm implicações no projeto de país e de sociedade e nas concepções de política pública, de educação e de formação humana. (CALDART, 2012, p. 257)

Nesse sentido, a Educação do Campo não pode se desvincular de sua materialidade de origem: a luta pela terra, pela vida, por uma agricultura que contenha a cultura e o manejo sustentável dos ecossistemas e a memória camponesa de resistência, de modo que a construção do seu Projeto Político-Pedagógico (PPP) e de escola esteja orientado para a formação de sujeitos lutadores e construtores do futuro, capazes de conhecer a realidade contraditória e de se engajar em um projeto de transformação de seu meio e da sociedade.

Conforme Caldart (2012, p. 265), podemos dizer que:

[...] no plano da práxis pedagógica, a Educação do Campo projeta futuro quando recupera o vínculo essencial entre formação humana e produção material da existência, quando concebe a intencionalidade educativa na direção de novos padrões de relações sociais, pelos vínculos com novas formas de produção, com o trabalho associado livre, com outros valores e compromissos políticos, com lutas sociais que enfrentam as contradições envolvidas nesses processos.

Por este motivo que as escolas do campo precisam superar a forma/conteúdo/valores escolares do capital, indo além das pedagogias que caracterizam as relações de subordinação/mando. A escola do campo, interessada na emancipação do campesinato, como fração da classe trabalhadora, promove a investigação de experiências vividas pelas/os estudantes, como ponto de partida das relações educativas (PEREIRA, 2015).

As bases pedagógicas que orientam a Educação do Campo se alinham com perspectivas da pedagogia socialista, Pedagogia do Oprimido e com a pedagogia do Movimento dos Trabalhadores Sem Terra, tendo em vista, materializar objetivos de formação e ação social coletiva voltadas aos interesses da classe trabalhadora e de suas novas gerações. Objetivando uma educação e uma escola contextualizadas com a realidade de trabalhadoras/es que lutam pela terra e por sua permanência nela, a educação do campo pressupõem a necessidade de que o trabalho, a luta social, a organização coletiva, a cultura e a bistória sejam matrizes formativas articuladas presentes nos processos educativos do campo (CALDART, 2017).

Com base nestas matrizes, os processos educativos adquirem uma perspectiva ressignificada do trabalho em seu sentido ontológico, como processo educativo criativo e humano, na sua relação dialética com a natureza. O trabalho, nessa perspectiva, vinculado aos conhecimentos escolares e científicos, possibilita que a cultura por ele produzida supere a sua forma capitalista histórica exploradora, do emprego, do trabalho flexível, autônomo e precário. Nesse 
caso, investe-se na associação de produtores livres que dominem conhecimentos para a complexa realização de atividades produtivas e de cooperação entre sujeitos do campo. Há uma aposta na apropriação, pelas/os trabalhadoras/es, de conteúdos sistematizados pelas ciências, técnicas e artes, que possam contribuir para a explicação das contradições existentes e para a busca de sua superação, juntamente com um embasamento crítico que possibilite a tomada de posição, frente aos processos desumanizantes, tanto individualmente ou como classe.

Desenvolver o senso de cooperação e de coragem pela luta social frente às contradições é um meio de articular e de mobilizar os sujeitos do campo a se envolverem nos acontecimentos de seu tempo, vinculando-se a um movimento social ou a um projeto de futuro, ainda que as condições materiais sejam obstáculos a essa mudança. A solidariedade ativa de classe, junto a um projeto de futuro faz da organização coletiva um meio importante para a luta pela construção de um mundo melhor para todas as pessoas, acessando os melhores caminhos para que isso aconteça, envolvendo toda a sociedade. Isto requer o cultivo da memória coletiva e a valorização do modo de vida camponês que tem sido desqualificado.

A Educação do Campo, nesse caso, tem o intuito de formar para uma consciência histórica de identidade de luta camponesa pela terra. Formação, esta que passa pelo cultivo da identidade dos sujeitos trabalhadores, seus valores e símbolos que auxiliam no enraizamento, na identificação e na afirmação dos traços que caracterizam a cultura camponesa frente ao desafio da reforma agrária e da luta contra o agronegócio, ameaçador da própria existência do modo de vida camponês.

\section{AGROECOLOGIA}

O termo Agroecologia, que diz respeito a formas de produção e modos de vida camponeses alinhados aos princípios ecológicos, tem sido empregado por um número crescente de instituições e movimentos sociais em diversos países (NORDER et al., 2016). Buscamos compreender a Agroecologia, neste tópico, a partir de três aspectos articulados: uma prática social, um movimento social e uma ciência que articula diferentes áreas de conhecimento (WEZEL et al., 2009).

Enquanto prática social, a Agroecologia tem a ver com experiências de produção agrícola que aproveitam o potencial endógeno do campo, sugerindo alternativas sustentáveis (SEVILLAGUZMÁN, 2004) que substituam práticas predadoras da agricultura industrial, pertencente ao modelo capitalista de desenvolvimento. As práticas agroecológicas priorizam a sustentação da relação entre os seres sociais com a terra, sementes e todos os seres que, igualmente aos humanos, compõem a natureza como totalidade. Podem ser práticas ancestrais e contemporâneas, desde que 
sejam reconhecidas e potencializadas nas inter-relações dos sistemas socioculturais e ambientais na produção.

Nesse processo, entram em sinergia intuições, saberes e crenças com outras dinâmicas naturais, com a finalidade de aumentar ou favorecer a complexidade e/ou utilidade daquilo que é produzido e/ou consumido. Conhecer a ciclagem de nutrientes, as interações entre animais e plantas, a função dos insetos no sistema, das formas de controle biológico de pragas e doenças, o melhoramento genético natural de espécies, enfim, as relações ecológicas e as possibilidades de aproveitamento de energia local é fundamental para a intervenção agroecológica. Somando a isso, ainda podemos mencionar as observações e o direcionamento destas interações desejadas para gerar estabilidade nas áreas de produção, visando a abundância (GUHUR; TONÁ, 2012).

Como prática, a Agroecologia pode coincidir em muitos aspectos com o início da agricultura (mais de dez mil anos atrás) e ser considerada como um legado decorrente do aprimoramento do trabalho de camponeses, ribeirinhos, indígenas e comunidades tradicionais. Tais sujeitos foram centrais no processo de domesticação e manejo das plantas e animais, no melhoramento de sementes e na invenção de sistemas agroalimentares eficientes, como as milpas mexicanas, as chinampas mesoamericanas e a agricultura de terraço andina (PEREIRA, 2015).

A Agroecologia refere-se, portanto, ao processo mútuo de interação co-evolutiva desses sujeitos com a terra e na terra, que, por meio do trabalho humano nutrido de potencial ecológico do conjunto de ecossistemas, produzem os agroecossistema. Segundo Altieri (2012, p. 105), “os agroecossistemas são comunidades de plantas e animais interagindo em seu ambiente físico e químico que foi modificado para produzir alimentos, fibras, combustíveis e outros produtos para consumo e utilização humana". O conhecimento das relações agroecossistêmicas que os camponeses acumularam é a base para a produção sustentável e permite, além de outras coisas, eliminar do processo produtivo o uso de insumos externos industriais tóxicos, contaminantes ou desequilibradores (HECHT, 1993).

Nesse sentido, é impossível dissociarmos a agrobiodiversidade dos contextos e das práticas socioculturais e econômicas que a envolve. As condições sociais e políticas oferecidas para que ocorra a interação entre seres humanos e ecossistemas, bem como, os fatores ambientais que incidem nesse processo, influenciam na biodiversidade dos resultados gerados nesta relação.

Nas sociedades capitalistas essas condições são adversas, tanto do ponto de vista ecológico, como socioeconômicos, pois o preceito de mercantilização geral da vida produz a desecologização dos saberes do trabalho e contraria os limites da natureza, tendendo a esgotar as próprias bases de sustentação da agricultura. De uma maneira mais ampla, o avanço da lógica de reprodução do capital no campo (agronegócio), baseadas no extrativismo desenfreado, no emprego 
de pacotes tecnológicos altamente deletérios para a natureza e comunidades, subordinando a agricultura à indústria e ao sistema financeiro (OLIVEIRA, 2007), produz impactos planetários (mudanças climáticas, camada de ozônio), ainda que, de efeito desproporcional aos países e as classes sociais, conforme a posição econômica.

Um dos grandes desafios relacionados à prática agroecológica camponesa, neste contexto capitalista, é a discrepância de investimentos públicos que, a partir de gestões do setor do agronegócio, tende a concentrar-se na produção de commodities, incentivando-se processos como a reforma agrária de mercado, regularização fundiária de grilagem de terras e inserção subordinada dos camponeses na lógica agroindustrial, seja como mão de obra, seja como consumidores dos pacotes tecnológicos, configurando-se mais uma forma de extração de renda da terra e de desmonte do território camponês. A ampliação do território do agronegócio, nesse sentido, pressupõe a eliminação do território camponês que inclui sua autonomia relativa ao mercado.

$\mathrm{Na}$ prática, o uso de sementes transgênicas e de mudas clonais, que se utilizam de intensa pulverização de agrotóxicos e o uso de fertilizantes artificiais contaminam o solo/água e dificultam que outras culturas e formas de produzir também se manifestem no entorno. Somado a isso, ainda podemos citar o roubo de terras comum no Brasil (grilagem) e a desqualificação, pelo aparato ideológico do agronegócio, do manejo agroecológico camponês como ultrapassado.

No Brasil, a Agroecologia como movimento social, tem suas bases no movimento de agricultura alternativa, ligado ao ambientalismo (PETERSEN, 2012), que ganhou força na década de 1970, contestando a agricultura que se tornou convencional dentro do capitalismo, evidenciando seus impactos deletérios sobre a natureza e o trabalho. Os grupos de intelectuais, ambientalistas, profissionais e estudantes organizaram, nas décadas seguintes, os Encontros Brasileiros e Regionais de Agricultura Alternativa, consolidando a noção de agroecologia e contribuindo para sua disseminação (PETERSEN, 2012).

Nos anos 2000, segundo Ribeiro et al. (2017), os movimentos sociais populares do campo incorporaram as reflexões sobre a Agroecologia em suas estratégias políticas, passando a contribuir também para o seu debate até os dias atuais. Como exemplo, podemos citar a Via Campesina, que organizou a campanha "As sementes são patrimônio da humanidade", e o Curso Básico de Educação e Agroecologia, com o tema "Agroecologia na Educação Básica nas Escolas do Campo: pressupostos teóricos, conteúdos, metodologia e avaliação", realizado em 2016, na Escola Popular de Agroecologia e Agrofloresta Egídio Brunetto, no extremo sul da Bahia (FERREIRA, 2018).

A Agroecologia tem se intensificado como luta de vários movimentos sociais do campo para ampliação da produção agroecológica da agricultura camponesa e familiar em assentamentos de reforma agrária. Defende os biomas e as comunidades locais, apoiando a luta pelo direito à 
Educação do Campo e valorização dos saberes destes grupos diante de sua experiência ancestral com a agricultura. Também, articula sua prática com a luta pela soberania alimentar na denúncia contra os agrotóxicos e seus impactos socioambientais, principalmente pela existência e pela expansão de seu território traduzida na luta pela reforma agrária popular.

Segundo Stedile (2012), existem diferentes modelos de reforma agrária segundo as experiências históricas e os interesses de diferentes países. Contudo, no Brasil a reforma agrária é inexistente em qualquer um de seus modelos. Por este motivo, os movimentos sociais do campo articulados na Via campesina, neste século XXI, estão defendendo uma reforma agrária popular, que afirma a necessidade de um amplo processo de desapropriação das maiores propriedades rurais brasileiras, estabelecendo-se um limite máximo, e sua distribuição à todas as quatro milhões de famílias camponesas sem-terra (ou com pouca terra) que vivem no meio rural.

Tal reforma, combina distribuição de terras com instalação de agroindústrias cooperativas e a adoção de novas técnicas agrícolas agroecológicas, que aumentem a produtividade das áreas e do trabalho, em equilíbrio com o ambiente, sem uso de venenos agrícolas, além de uma política nacional de mecanização com pequenas máquinas para diminuir o esforço físico, sem perder a mão de obra. Ela ainda prevê a democratização da educação formal, garantindo o acesso à escola desde o Ensino Fundamental até o Ensino Superior, com erradicação completa do analfabetismo de pessoas adultas e um amplo programa de valorização das manifestações culturais do meio rural (festas, músicas, comida) (STEDILE, 2012).

Ainda que algumas perspectivas conservadoras - presentes no governo, na imprensa e na academia - afirmem não haver necessidade de uma reforma agrária e que o aumento da produtividade no campo pela sua modernização já resolve, portanto, o problema agrário brasileiro, Stedile (2012) afirma que a forma como a sociedade brasileira organiza o uso, a posse e a propriedade dos bens da natureza ocasionam graves problemas agrários, de natureza econômica, social, política e ambiental.

Para o autor, o elevado índice de concentração da propriedade da terra e de sua produção se dá pelo fato de que: apenas $1 \%$ dos proprietários controla $46 \%$ de todas as terras e apenas $8 \%$ dos estabelecimentos produzem mais de $80 \%$ das commodities agrícolas exportadas. Além disso, há problemas no uso das terras, pois $80 \%$ de todas as terras são utilizadas apenas para produzir commodities de soja, milho e cana-de-açúcar, e a pecuária extensiva; sem contar "a dependência econômica externa a que a agricultura brasileira está submetida, por causa do controle do mercado, dos insumos e dos preços pelas empresas agrícolas transnacionais"; somada à subordinação ao capital financeiro que adianta recursos, cobra juros e divide a renda gerada na agricultura (STEDILE, 2012, p. 644). 
Esses dados revelam a extrema desigualdade social no meio rural, gerada por esta estrutura econômica capitalista, com sete milhões de pessoas vivendo em pobreza absoluta e 14 milhões de pessoas adultas analfabetas. Além disso, o autor afirma que a maioria dos jovens da área rural "não têm acesso ao ensino fundamental completo (oito anos), nem ao ensino de nível médio e muito menos ao ensino superior" (STEDILE, 2012, p. 645). Há, também, um passivo ambiental que infringe leis do Código Florestal, gerando multas a fazendeiros brasileiros, no valor total aproximado de 8 bilhões de reais, em 2011, que nunca foram pagas.

Tais fatores justificam e exigem atuações coletivas organizada dos movimentos sociais, para que estes reúnam forças e estratégias políticas para a realização de uma reforma agrária popular, que supere os programas de colonização e distribuição de terras públicas em fronteiras agrícolas, sobretudo, superando aquela que privilegia sociedades anônimas (empresas capitalistas), além de sua utilização apenas como sinônimo de desapropriação de algumas fazendas e da política de assentamentos rurais (estas últimas são ações fundamentais, embora ainda insuficientes) (STEDILE, 2012).

Nesse sentido, diferentes movimentos sociais $^{7}$ e suas redes de mobilização têm se organizado para a criação de espaços de debates, de divulgação e de alinhamentos de estratégias para o desenvolvimento de práticas agroecológicas. Os fóruns, congressos, conferências etc., a criação da Associação Nacional de Agroecologia (ANA), Encontros Nacionais de Agroecologia (ENAs), além de outras redes de comunicação que projetam a agricultura camponesa se sobressaem como principais meios de articulação de informações sobre a importância de soberania alimentar e energética, bem como, sobre a denúncia dos malefícios dos agrotóxicos na alimentação (causada pelo modelo do agronegócio) e a crítica ao sistema de exploração capitalista.

Ainda é possível ressaltar os esforços para a construção de políticas públicas ${ }^{8}$ que favoreçam a produção e a comercialização de produtos frutos do trabalho camponês, com a validação da certificação coletiva dos produtos pelos pares para a comercialização em feiras e outros espaços públicos, bem como, estratégias de possíveis negociações com diferentes setores, sem perder de vista o objetivo de uma reforma agrária popular, que luta por educação, terra para (re)produção da vida e soberania alimentar.

\footnotetext{
${ }^{7}$ Ações sociais coletivas de caráter sociopolítico e cultural, que viabilizam formas distintas de organização popular para expressar as suas demandas por meio diferentes estratégias, que vão desde denúncias a pressões diretas como passeatas, marchas, utilizando-se de ferramentas de comunicação e de articulação para criar redes mobilização (GOHN, 2008).

${ }^{8}$ No caso brasileiro, podemos ilustrar no contexto da agroecologia algumas políticas públicas de desenvolvimento rural pelo governo federal, como é o caso do Programa de crédito para a agricultura familiar (Pronaf Agroecologia), Política Nacional de Assistência Técnica e Extensão Rural (PNATER), Política Nacional de Agroecologia e Produção Orgânica (PNAPO - Decreto 7.794 de 2012), entre outros programas de agroecologia em âmbito estadual.
} 
Todas essas mobilizações enfrentam diariamente as estratégias hegemônicas de articulações transnacionais que privatizam os bens ambientais, explorando as/os trabalhadoras/es e monopolizando o capital e o território, com esforços exaustivos de construção ideológica de que o agronegócio é a única forma de suprir as demandas alimentares da sociedade, utilizando-se de veículos de comunicação em massa dominados pelo discurso do agronegócio (Agro é pop, agro é vida!).

Tal construção ideológica confunde as reais diferenças entre as intencionalidades do agronegócio e da Agroecologia. Somado a isso, ainda há a articulação de empresas, parceiros e clientes da agroindústria pela Associação Brasileira do Agronegócio que disputam além das práticas produtivas, o próprio conceito de Agroecologia, bem como, o crescente processo de certificação burocrática e onerosa dos produtos ecológicos do mercado verde que expande com base no discurso da sustentabilidade empresarial.

$\mathrm{Na}$ contramão da sustentabilidade empresarial, a Agroecologia tem sido considerada uma ciência que oferece bases para um novo paradigma de sustentabilidade do campo agroecológico. Tal paradigma contrapõe o modelo convencional de desenvolvimento rural, associado ao crescimento da agricultura capitalista, a expropriação de pequenas/os produtoras/es e o êxodo rural.

Conceitualmente, a Agroecologia é uma construção recente, que se popularizou nos anos de 1980 como disciplina acadêmica, sendo dois os principais teóricos na vertente estadunidense: Miguel Altieri e Stephen Gliessman.

Inicialmente, sua concepção científica apoiava processos de transição para estilos de agricultura de base ecológica ou sustentável, apropriados culturalmente, socialmente justos e viáveis economicamente, emergindo como uma disciplina que previa manejar agroecossistemas. Nas palavras de Altieri (2012, p. 104):

A agroecologia emerge como uma disciplina que disponibiliza os princípios ecológicos básicos sobre como estudar, projetar e manejar agroecossistemas que sejam produtivos e ao mesmo tempo conservem os recursos naturais, assim como sejam culturalmente adaptados e social e economicamente viáveis.

Essa vertente enfoca a Agroecologia para além do uso de práticas alternativas de baixa dependência de agroquímicos, ou de aportes externos de energia. Ela enfatiza agroecossistemas complexos nos quais as interações entre seus componentes biológicos "promovem os mecanismos para que os próprios sistemas subsidiem a fertilidade do solo, sua produtividade e a saúde dos cultivos" (ALTIERI, 2012, p. 105).

Para a vertente conhecida como escola europeia, a Agroecologia surgiu da interação entre disciplinas científicas e as comunidades rurais, principalmente da América Latina. Sobressaem nesta 
vertente, os estudos de Eduardo Sevilla-Guzmán e Manuel González de Molina, ambos ligados ao Instituto de Sociología y Estudios Campesinos (ISEC), da Universidade de Córdoba. Suas publicações datam de 1980 e representam uma abordagem mais sociológica que busca uma caracterização agroecológica do campesinato (GUHUR; TONÁ, 2012).

Essa escola auxilia na compreensão multidimensional da Agroecologia, reunindo um conjunto de teorias e metodologias que possibilitam a conexão entre o saber popular e o saber científico. Além disso, ela acrescenta outras seis dimensões da sustentabilidade, sendo elas: ecológica, econômica, social, cultural, política e ética. Nas palavras de Sevilla-Guzmán (2011, p. 13):

\begin{abstract}
A agroecologia pode ser definida como o manejo ecológico dos recursos naturais por meio de formas coletivas de ação social que apresentam alternativas a atual crise civilizatória. E isso mediante propostas participativas desde os âmbitos da produção e circulação alternativa de seus produtos, pretendendo estabelecer formas de produção e consumo que contribuam para encarar a deterioração ecológica e social gerada pelo neoliberalismo atual. Sua estratégia tem uma natureza sistêmica, ao considerar o lote (chácara, sítio, etc), a organização comunitária, e os demais âmbitos de relação das sociedades rurais articulados em torno da dimensão local, na qual se encontram os sistemas de conhecimento (local, camponês e/ou indígena) portadores do potencial endógeno que permite potencializar a biodiversidade ecológica e sociocultural. (Tradução nossa)
\end{abstract}

$\mathrm{Na}$ complementação das ênfases apresentadas por estas duas vertentes em que a Agroecologia vem se consolidando, encontram-se, pelo menos, quatro áreas que influenciaram o pensamento agroecológico, organizadas por Hecht (1993, p. 08-17), a saber: as ciências agrícolas, o ambientalismo, o estudo sobre o modelo de desenvolvimento e os estudos dos sistemas tradicionais da produção indígena.

Uma síntese destas áreas nos auxilia a compreender a integração da Agroecologia com diferentes subcampos e o amadurecimento de seu potencial inter-transdisciplinar. Nesse sentido, começando pelo estudo das ciências agrícolas, em particular a Ecologia, a autora afirma que esta permitiu contestar a agronomia convencional como técnica mais eficiente para a agricultura, ao evidenciar a importância da microbiologia dos solos e a nutrição de plantas (PRIMAVESI, 2016).

Já o ambientalismo trouxe grande contribuição à Agroecologia, sobretudo, no questionamento crítico do modelo de produção e consumo pautados pelo capitalismo, além de evidenciar, entre outros, os impactos e as contaminações da agricultura moderna, no interior da relação sociedade-ambiente, mobilizando propostas para a formação de uma nova sociedade descentralizada, pautada em princípios socioambientais de autossuficiência energética, sustentabilidade e uma tecnologia apropriada aos países em desenvolvimento (HECHT, 1993). 
Os estudos sobre o modelo de desenvolvimento agrícola adotado nos países do Terceiro Mundo e a utilização massiva de tecnologias importadas na produção agrícola revelavam aumento dos riscos para agricultoras/es, esgotamento dos solos, concentração de terras e recursos produtivos. Tais riscos afetam e provocam ainda mais pobreza, desigualdade social, dependência e marginalização destes países e grupos sociais, ao invés de seu desenvolvimento (HECHT, 1993).

$\mathrm{O}$ aprofundamento das investigações sobre os sistemas tradicionais de produção indígenas e camponeses pela antropologia e pela Geografia evidenciou diferentes lógicas e mecanismos que garantiam a sustentabilidade dos sistemas produtivos, como: a diversificação de culturas, os vários usos e manejos dos recursos; a complexidade de fatores concorrentes, o conhecimento ecológico dessas comunidades, suas noções de eficiência e produtividade; a integração de espécies florestais e pastagens à lavoura (agrossilvipastoril) (HECHT, 1993).

Estes e outros campos articuladamente contribuíram para que a Agroecologia seguisse na direção de se tornar uma ciência de perspectiva transdisciplinar com pluralidade epistemológica, destacando-se pela importância dada às experiências e às lutas dos povos do campo (agricultoras/es, indígenas, quilombolas), aos seus saberes com o ambiente (LEFF, 2002) e à sua articulação com os conhecimentos científicos, consolidando-se como uma proposta de um novo paradigma frente ao do desenvolvimento rural, com vistas ao melhoramento integral da produção aliada à cultura, trabalho e a conservação socioambiental.

A Agroecologia como uma matriz disciplinar integradora e nutrida por diferentes conhecimentos, parte das experiências do campo, no campo e com as pessoas que nele vivem para assim elaborar, aprimorar e/ou refutar conhecimentos científicos. Tais conhecimentos têm potencialidade de contribuir com a formação de estudantes, técnicos e agricultoras/es, com propostas de projetos de extensão articulados com formações técnica e política das/os estudantes que poderão conhecer contradições da realidade do campo brasileiro e seus modelos em disputa, com atividades de pesquisa, ensino e extensão que propiciem o diálogo de saberes entre os diferentes sujeitos do processo educativo.

Nesse sentido, os principais desafios relacionados aos aspectos que envolvem o conceito de Agroecologia têm sido a sua apropriação para traduzir práticas e técnicas do mercado verde ou agronegócio orgânico que promovem a simples substituição de insumos industriais por outros mais ecológicos. Esta apropriação esvazia de sentido político-social, o conceito de Agroecologia como é o caso de empresas e megaempreendimentos que afirmam realizar projetos agroecológicos em assentamentos de reforma agrária e de educação ambiental, junto à rede pública de ensino das escolas rurais e outros espaços. Suas ações estão na direção de valorizar práticas do agronegócio 
para o desenvolvimento do campo (gerando empregos, formação e tecnologia) e do incentivo de comportamentos ecologicamente corretos, como solução para a crise ambiental.

Além disso, segundo Whitaker; Fiamengue (2002), outro desafio enfrentado na produção e valorização de conhecimento agroecológico é a própria desarticulação da pesquisa, ensino e extensão nas universidades, o desigual peso de importância entre elas e o direcionamento dos temas de pesquisa relacionados ao agronegócio, com baixo financiamento na área de Agroecologia. Além disso, os projetos de extensão e o apoio técnico junto aos sujeitos do campo, por exemplo, ainda se pautam majoritariamente em uma perspectiva assistencialista, autoritária e pouco dialógica.

Mesmo com tudo isso, não há como deixar de mencionar a existência de diferentes práticas e esforços significativos de grupos universitários, institutos e outras organizações que atuam na perspectiva de extensão como comunicação, como apontada por Freire (1992), além de importantes pesquisas comprometidas socioambientalmente, somadas à conquista de políticas públicas na Educação do Campo, pautada por diretrizes elaboradas a partir de demandas da população camponesa, como é o caso das LEdoCs e de outros cursos superiores ou técnicos em agroecologia.

\section{CONSIDERAÇÕES FINAIS}

A partir das reflexões anteriormente apresentadas, compreendemos que as categorias "Educação do Campo" e "Agroecologia" indicam questões comuns, tendo em vista os desafios teórico-práticos envolvidos na construção contra hegemônica de sociedades sustentáveis, justas e igualitárias.

Identificamos, ao sistematizar as categorias estudadas, que o movimento ambientalista pode ser uma base para a Agroecologia, bem como, as discussões sobre desenvolvimento sustentável e a disputa por modelos de desenvolvimento do campo articulam a Agroecologia à Educação do Campo.

No que diz respeito à Educação do Campo, pudemos verificar uma nítida intencionalidade de reconhecer, desvelar e superar situações de opressão dos diferentes povos, etnias e grupos sociais ligados intimamente à terra. Esta intencionalidade nos parece fundamental para a práxis individual e coletiva em relação aos direitos humanos e da natureza, podendo dar origem a outros processos de transformação protagonizados pelos próprios sujeitos do campo, que, em defesa da reforma agrária popular, projetam um outro futuro para a classe trabalhadora e para sociedades sustentáveis. A matriz formadora do trabalho, ao dialogar com a Agroecologia em seu tripé (de ciência, movimento e prática), corrobora com esta intencionalidade. 
Os desafios enfrentados pela Educação do Campo e pela Agroecologia no contexto do agronegócio têm relação com o processo hegemônico de conversão da agricultura e da educação em mercadorias, sobrepondo seus valores de uso (criação e socialização de saberes com e no ambiente, alimentação, cultura etc.), aos valores de troca, com vistas ao acúmulo de capital e dominação cultural para a permanência de poder. A Educação do Campo, neste caso, passa a disputar além dos fundos públicos, também a sua orientação bancária ou transformadora, embora sua predominância esteja na direção da formação profissional alienante, pouco útil ao contexto de humanização da classe trabalhadora.

Contrapondo este tipo de educação, a Educação do Campo aposta na formação omnilateral, tendo o trabalho como parte constituinte do processo educativo, na preparação intencional da formação de personalidade dos que internalizam, desde a infância, a sua condição intrínseca com a natureza. Compreender os meios de produção e reprodução da vida como ação educativa humanizadora é fundamental para evidenciar contradições do trabalho capitalista assalariado, criando formas de superá-las, substituindo-as. O objetivo é que trabalhadoras/es se apropriem do conhecimento instrumental acumulado e dos meios coletivos de produção para poder, de posse dos instrumentos da ciência, Filosofia, arte, bem como, de suas outras importantes formas de consciência sobre o mundo (senso comum, mitos, religiões), possam também se apossar dos frutos de seu trabalho.

A Agroecologia, por sua vez, compreendida como um conjunto de práticas específicas de produção agrícola com base ecológica, que concebe múltiplas formas de manejos agroecossistêmicos, a partir da articulação de diferentes saberes populares e científicos; uma ciência que reúne diferentes campos de conhecimento, inclusive os ancestrais e que se contrapõem ao modelo reproducionista de conhecimento e da produção agrícola convencional (químicomecanizada), servindo de base para apoiar os processos de transição a modos de produção ecológicos ou sustentáveis; e, um movimento social e político que articula diferentes frentes de ação para transformação socioambiental que coaduna na luta por produção de alimentos saudáveis de bases sustentáveis, pela soberania alimentar, pela educação pública de qualidade do campo e pela reforma agrária popular, podendo contribuir para a formação de um novo paradigma de ser, pensar e trabalhar ao nos apresentar, além de outras possibilidades, a de produzir com e no ambiente, de forma a relacionar demandas sociais e ambientais de um determinado território.

No movimento de pensar a Educação do Campo e a Agroecologia no sentido dialético da natureza humana, de suas relações e da humanização da natureza, em coevolução, seguimos na direção de ultrapassar as ações paliativas que podem ser atribuídas a estas categorias, com vistas a superar tal crise societária existente, podendo realizá-la de forma dialógico-crítica em diferentes 
espaços, aproveitando a potencialidade dessas categorias em acessar o mesmo terreno da hegemonia, para conhecer o interior dos complexos mecanismos institucionais que fazem funcionar o sistema de base na dominação.

\section{REFERÊNCIAS}

ALTIERI, Miguel A. Agroecologia: as bases científicas da agricultura alternativa. 3. ed. São Paulo; Rio de Janeiro: Expressão Popular, AS-PTA, 2012.

CALDART, Roseli Salete. Educação do Campo. In: CALDART, Roseli Salete et al. (Orgs.). Dicionário da Educação do Campo. Rio de Janeiro: Escola Politécnica de Saúde Joaquim Venâncio; Expressão Popular, 2012. p. 257-265.

CALDART, Roseli Salete et al. (Orgs.). Dicionário da Educação do Campo. Rio de Janeiro: Escola Politécnica de Saúde Joaquim Venâncio; Expressão Popular, 2012.

CALDART, Roseli Salete. Trabalho, Agroecologia e educação politécnica nas escolas do campo. In: PIRES, João Henrique et al. (Orgs.). Questão agrária, cooperação e Agroecologia. Vol. 3. Uberlândia: Navegando, 2017. p. 263-328.

CAMINI, Isabel. Escola itinerante: na fronteira de uma nova escola. São Paulo: Expressão Popular, 2009.

CARVALHO, Horácio Martins de. O camponês, guardião da socioagrobiodiversidade. Curitiba, 2013. (Mimeo).

FERNANDES, Bernardo Mançano. Sobre a tipologia de territórios. In: SAQUET, Aurélio Marcos; SPOSITO, Eliseu Savério (Orgs). Territórios e territorialidades: teorias, processos e conflitos. São Paulo: Expressão Popular, 2009. p. 197-215.

FERNANDES, Bernardo Mançano; MOLINA, Mônica Castagna. O campo da educação do campo In: MOLINA, Mônica Castagna; JESUS, Sônia Meire Santos Azevedo de (Orgs.).

Contribuições para a construção de um projeto de Educação do Campo. Brasília:

Articulação Nacional "Por Uma Educação do Campo", 2004. p. 53-91.

FERREIRA, Caroline Lins Ribeiro. Educação Ambiental dialógico-crítica e sua relação com a prática da Agroecologia e da Educação do Campo no território do extremo sul da Bahia: entre o descompasso e o desafio de transformação. 2018. 215 f. Tese (Doutorado em Ciências Ambientais) - Centro de Ciências Biológicas e da Saúde. Universidade Federal de São Carlos, São Carlos, 2018.

FREIRE, Paulo. Extensão ou Comunicação? 10. ed. Rio de Janeiro: Paz e Terra, 1992.

FREIRE, Paulo. Pedagogia do oprimido. 31. ed. Rio de Janeiro: Paz e Terra, 2001.

FRIGOTTTO, Gaudêncio. Educação omnilateral. In: CALDART, Roseli Salete et al. (Orgs.). Dicionário da Educação do Campo. Rio de Janeiro: Escola Politécnica de Saúde Joaquim Venâncio; Expressão Popular, 2012. p. 265-272. 
GOHN, Maria da Glória. O protagonismo da sociedade civil: movimentos sociais, ONGs e redes solidárias. 2. ed. São Paulo: Cortez, 2008.

GUHUR, Dominique Michèle Perioto; TONÁ Nilciney. Agroecologia. In: CALDART, Roseli Salete et al. (Orgs.). Dicionário da Educação do Campo. Rio de Janeiro; São Paulo: Escola Politécnica de Saúde Joaquim Venâncio; Expressão Popular, 2012. p. 57-64.

HECHT, B. Suzanna. A evolução do pensamento agroecológico. Agroecologia e desenvolvimento, Rio de Janeiro, ano I, nº 1, p. 4-20, ago., 1993.

LEFF, Enrique. Agroecologia e saber ambiental. Agroecologia e Desenvolvimento Rural Sustentável, Porto Alegre, v. 3, n. 1, p. 36-51, jan./mar., 2002.

LIMA, Telma Cristiane Sasso de; MIOTO, Regina Célia Tamaso. Procedimentos metodológicos na construção do conhecimento científico: a pesquisa bibliográfica. Revista Katálysis, Florianópolis, v. 10, v. 10, n. esp. p. 37-45, 2007.

MÉSZARÓS, Isteván. A educação para além do capital. São Paulo: Boitempo, 2006.

MOLINA, Mônica Castagna. Políticas públicas. In: CALDART, Roseli Salete et al. (Orgs.). Dicionário da Educação do Campo. São Paulo: Expressão Popular, 2012. p. 585-593.

NORDER, Luiz Antonio et al. Agroecologia: polissemia, pluralismo e controvérsias. Ambiente \& Sociedade, São Paulo, v. XIX, n. 3, p. 01-20, jul.-set., 2016.

OLIVEIRA, Ariovaldo Umbelino. Modo de produção capitalista, agricultura e reforma agrária. São Paulo: FFLCH, 2007.

OLIVEIRA, Lia Maria Teixeira; CAMPOS, Marília. Educação Básica do Campo. In: CALDART, Roseli Salete et al. (Orgs.). Dicionário da Educação do Campo. Rio de Janeiro: Escola Politécnica de Saúde Joaquim Venâncio; Expressão Popular, 2012. p. 237-244.

PEREIRA, Kelci Anne. Educação do Campo e rede de movimentos no sudeste do Pará: Agroecologia e cooperativismo na relação entre trabalho e educação. 2015. 300 f. Tese (Doutorado em Educação) - Faculdade de Educação. Universidade de São Paulo, São Paulo, 2015.

PETERSEN, Paulo. Agriculturas alternativas. In: CALDART, Roseli Salete et al. (Orgs.). Dicionário da educação do campo. Rio de Janeiro: Escola Politécnica de Saúde Joaquim Venâncio; Expressão Popular, 2012. p. 40-46.

PRIMAVESI, Ana. Manual do solo vivo: solo sadio, planta sadia, ser humano sadio. 2. ed. São Paulo: Expressão Popular, 2016.

RIBEIRO, Marlene; Movimento camponês, trabalho e educação: liberdade, autonomia, emancipação: princípios fins da formação humana. 2. ed. São Paulo: Expressão popular, 2013.

RIBEIRO, Dionara Soarez et al. Agroecologia na Educação Básica: questões propositivas de conteúdo e metodologia. São Paulo: Expressão Popular: São Paulo, 2017. 
SANTOS, Clarice Aparecida dos. Programa Nacional de Educação na Reforma Agrária (PRONERA). In: CALDART, Roseli Salete et al. (Orgs.). Dicionário da Educação do Campo. Rio de Janeiro: Escola Politécnica de Saúde Joaquim Venâncio; Expressão Popular. 2012. p. 631 639.

SEVILLA-GUZMÁN, Eduardo. La agroecología como estrategia metodológica de transformación social. Instituto de Sociología y Estudios Campesinos de la Universidad de Córdoba. España, 2004.

SEVILLA-GUZMÁN, Eduardo. Sobre los orígenes de la agroecologia em el pensamiento marxista e libertário. La Paz-Bolívia: Agruco/Plural Editores/Center for Development ans Environment/NCCR, 2011.

STEDILE, João Pedro. Reforma agrária. In: CALDART, Roseli Salete et al. (Orgs.). Dicionário da Educação do Campo. Rio de Janeiro: Escola Politécnica de Saúde Joaquim Venâncio; Expressão Popular, 2012. p. 659-668.

WEZEL, A. et al. Agroecology as a science, a movement and a practice: a review. Agronomy for Sustainable Development, vol. 29, p. 503-515, 2009.

WILLIAMS, Raymond. Marxismo e Literatura. Trad. Eliane Stephan. Rio de Janeiro: Zahar, 1979.

WHITAKER, A.; FIAMENGUE, Elis C. Ciência e ideologia: as armadilhas do preconceito. In: WHITAKER, Dulce C. A. (Orgs.). Sociologia Rural: questões metodológicas emergentes. Presidente Venceslau: Letras à Margem, 2002. p. 19-32. 